Article

\title{
Immunization Status against Measles, Mumps, Rubella and Varicella in a Large Population of Internationally Adopted Children Referred to Meyer Children's University Hospital from 2009 to 2018
}

\author{
Angela Bechini ${ }^{1, *} \mathbb{0}$, Sara Boccalini ${ }^{1, *}{ }^{1}$, Cecilia Maria Alimenti ${ }^{1}$, Paolo Bonanni ${ }^{1}$, \\ Luisa Galli ${ }^{1,2}$ and Elena Chiappini ${ }^{1,2}$ \\ 1 Department of Health Sciences, University of Florence, Viale GB Morgagni, 48-50134 Florence, Italy; \\ cecilia.alimenti@stud.unifi.it (C.M.A.); paolo.bonanni@unifi.it (P.B.) \\ 2 Meyer Children's University Hospital, Viale Pieraccini 24-50139 Florence, Italy; luisa.galli@unifi.it (L.G.); \\ elena.chiappini@unifi.it (E.C.) \\ * Correspondence: angela.bechini@unifi.it (A.B.); sara.boccalini@unifi.it (S.B.); Tel.: +39-055-2751084 (S.B.)
}

Received: 27 December 2019; Accepted: 25 January 2020; Published: 28 January 2020

\begin{abstract}
Control of vaccine preventable diseases (VPDs) is a challenge for healthcare systems. Different studies highlighted the suboptimal immunization of internationally adopted children (IAC). To evaluate the immunization status against measles, mumps, rubella (MMR), and varicella (V) in a large cohort of IAC, data at first screening visit of all IAC ( $<18$ years) consecutively referred to Meyer Children's University Hospital (Florence, Italy) from 2009 to 2018 were collected and analyzed. In total, 1927 children (median age: 5.99 years, interquartile range: 3.33-8.21) were enrolled. More than half of IAC were unprotected against MMR-V. The reliability of the vaccination documentation of the country of origin was poor, since more than a quarter of the IAC serologically tested were not protected against MMR-V, despite the vaccination documentation attesting previous vaccination. This was significantly more pronounced in children aged 15-18 years and in those originating from Africa. High rate of discordant serological results/documentation brings up questions regarding the optimal management of IACs, and suggests a rapid, careful, and complete assessment of immunization status timely after IAC's arrival. Serological testing of IAC of all ages followed by vaccination of seronegative children should be provided.
\end{abstract}

Keywords: seroprevalence; immunological status; vaccination; internationally adopted children; measles; mumps; rubella; varicella

\section{Introduction}

The control of vaccine preventable diseases (VPDs), such as measles or varicella, is a priority for healthcare systems. Outbreaks have been reported worldwide in recent years due to insufficient immunization coverage among the general population [1]. Accordingly, recent epidemiological data on VPDs in the European Union and European Economic Area (EU/EEA) demonstrate ongoing transmission in the context of insufficient vaccine coverage [1].

For instance, measles continues to be a threat in EU/EEA countries. From 1 January 2019 to 14 July 2019, 10,958 cases were reported in adults and children by the European Centre for Disease Prevention and Control [2,3]. The highest numbers were described in France, Bulgaria, Italy, Poland, and Lithuania [4]. In fact, Italy never reached the elimination status (interruption for at least 36 months). There were 1605 cases of measles and 19 cases of rubella reported in Italy during 2019 from the 1 January to the 31 October [5]. 
Various studies highlighted the need to maintain protective antibody titers levels in order to reach the thresholds of herd immunity for those vaccines for which herd immunity is possible, such as measles, mumps, rubella, and varicella (MMR-V) [1,6]. The threshold to be reached and maintained to ensure the herd immunity effect for MMR and V is $95 \%$ of vaccination coverage for 2 doses as established by the Italian National Immunization Programme (NIP) [7].

The Italian NIP is one of the most complete worldwide. However, in 2018, the vaccination coverage at 24 months of age for measles, mumps, and rubella was 93\% and for varicella was 74\% [8]. As a matter of fact, the herd immunity threshold for varicella in Italy was estimated around $70 \%$ according to Nardone et al [9].

Only in 2017 varicella's vaccine was introduced nationally [7]. The universal varicella vaccination was introduced progressively in some regions since 2003 [10].

Nationally, varicella's vaccination was recommended starting from 2017. In Tuscany, it was introduced since 2008 showing reduction of notification and hospitalization for varicella with a varicella coverage of 76-84\% from 2010-2012 [10-12].

In 2018, 1394 children were internationally adopted in Italy. Italy is the second nation at a global level with the highest rate of international adoptions behind the United States of America [13].

The Italian NIP recommends updating of the vaccination of migrants, including internationally adopted children (IAC), as soon as possible after their arrival, in order to prevent the spread of VPDs. In fact, a large proportion of IAC are likely to be susceptible to VPDs because of suboptimal immunization [14,15]: Children may be unvaccinated, partially vaccinated, or their immune status may be uncertain or unknown [16]. Moreover, their native country and adoptive country may have different immunization policies and schedules [17-20].

Proper documentation of immunization is a worldwide problem for IAC and also for migrants and asylum seekers [21].

Few studies are available reporting the percentage of IAC with protective antibody titers for VPDs. Protective antibody titers were reported in 12-95\% of IAC for measles, in $61-94 \%$ for rubella, and in $48-79 \%$ for mumps [14,19,20,22-27]. Antibody levels for varicella varied from 30-100\% $[14,19,20,24-27]$. Updated information regarding the vaccination status of IAC is of paramount importance in order to support decisions regarding vaccination programs soon after arrival in the adoption country.

Therefore, the aim of the current study was to analyze measles-mumps-rubella-varicella (MMRV) vaccination documentation available and immunological status in a large population of IAC referred to a single center in Tuscany (Italy) over a 10-year period.

\section{Materials and Methods}

\subsection{Study Population}

Between January 2009 and December 2018, we enrolled all the IAC consecutively referred to the Meyer Children's University Hospital by their adoptive parents, who consented to the screening evaluation. These children were assessed during the first evaluation, following the protocol recommended by the Italian national working group on migrant children (GLNIB) [19], as previously described [19] in particular focusing on immunization status.

Italian adopted children were excluded from the study. Conversely, IAC from all over the world were included if they were under 18 years of age and who had at least one serological test among measles, mumps, rubella, and varicella performed at the first evaluation. In addition, IAC whose parents did not sign consent were excluded from the study.

The study received approval by Meyer Children's University Hospital Ethics Committee, the Ethical Code Number is 15/2010. Parents who consented to their adoptive children participating in the study have signed a written informed consent. 


\subsection{Study Design}

This is a retrospective monocentric study. For each child included in the study, the following information was collected and entered in an electronic database, following a standard operative protocol for IAC developed internationally and adopted at Meyer Children's University Hospital [19,26,28]. The electronic database was a secured system to protect patient information. Briefly, the following information was retrieved for the purpose of the present study: Country of origin, gender, age at first observation, vaccine documentation for MMRV, results of serological tests for measles, mumps, rubella, and varicella. At the first evaluation, all the children underwent a venepuncture and laboratory assessment including serologic tests. Staff involved for the venepuncture and laboratory assessment were appropriately trained to do so.

All the other laboratory examinations were performed in the same laboratory at the Meyer Children's University Hospital, using standardized techniques and according to manufacturers' instructions.

In particular, serology tests for measles, rubella, varicella, and mumps were performed using a chemiluminescent immunoassay (CLIA) technology (LIAISONXL System, DiaSorin, Saluggia (VC), Italy) with a definition of seropositive samples when their antibody titers were $>16.5 \mathrm{mIU} / \mathrm{mL}$ for measles, $>15 \mathrm{IU} / \mathrm{mL}$ for rubella, $>165 \mathrm{mIU} / \mathrm{mL}$ for varicella, and $>11 \mathrm{AU} / \mathrm{mL}$ for mumps.

\subsection{Seroprevalence of Antibody Protection against Measles, Mumps, Rubella, and Varicella}

Children were subdivided according to age in five groups ( $<1 \mathrm{y}, 1-4 \mathrm{y}, 5-9 \mathrm{y}, 10-14 \mathrm{y}, 15-18 \mathrm{y})$ and classified as protected (seropositive) or unprotected (seronegative) against each specific VPD on the basis of serotesting results. Antibody seroprevalence for each age group was calculated and expressed as a percentage.

\subsection{Concordance between Vaccine Documentation and Serotesting Results}

Vaccine documentation was assessed, considering the number of doses recorded and the concordance between the available documentation and serotesting results for measles, mumps, rubella, and varicella. These data were recorded and entered in tables.

\subsection{Statistical Analysis}

Data were reported as median and interquartile range (IQR) or absolute numbers and percentages. Fisher exact test and Chi-square test were used to compare categorical variables, as appropriate. All statistical analyses were carried out using the SPSS (Statistical Package of Social Sciences, Chicago, IL) for Windows software program version 19.0. A $p$ value $<0.05$ was considered significant.

\section{Results}

\subsection{Characteristics of the Study Population}

In the decade 2009-2018, 2200 IAC from 64 countries were assessed for post-adoption screening. Of this initial group, 1927 were eligible for our study, while 273 were excluded from the evaluation because at least one serological test result was not available.

Considering serology results and/or documentation available, 1870 IAC were assessed for measles, 1868 for rubella, 631 for varicella, and 844 for mumps. Thus, $96.9 \%$ and $97 \%$ of the study population were included in the study for rubella and measles, respectively. Of the study population, $43.8 \%$ was included for mumps, whereas only $32.7 \%$ of the population was included in the study for varicella immunization status. The median age at first evaluation was 5.99 (IQR: $3.33-8.21$ ) years, $40.1 \%$ of the children were girls (773/1927) (Table 1). 
Table 1. Characteristics of the study population by continent of origin, gender, and median age.

\begin{tabular}{cccccc}
\hline & Africa & Americas & Asia & Europe & Total \\
\hline Population $(n)$ & $347(18 \%)$ & $419(21.7 \%)$ & $384(19.9 \%)$ & $777(40.3 \%)$ & $1927(100 \%)$ \\
Median age $(y)$ & 5.19 & 7.37 & 4.81 & 6.19 & 5.99 \\
IQR & $2.66-6.79$ & $5.30-9.34$ & $2.01-7.06$ & $3.73-8.26$ & $3.33-8.21$ \\
Females $(n)$ & $145(41.8 \%)$ & $193(46.1 \%)$ & $175(45.6 \%)$ & $260(33.5 \%)$ & $773(40.1 \%)$ \\
Males $(n)$ & $202(58.2 \%)$ & $226(53.9 \%)$ & $209(54.4 \%)$ & $517(66.5 \%)$ & $1154(59.9 \%)$ \\
\hline
\end{tabular}

Forty percent of the IAC were adopted from Europe (777/1927), most of them were from Russia; 21.7\% from Central or South America (419/1927); 19.9\% were adopted from Asia (384/1927); 18\% from Africa (347/1927) (Table 1). The most represented countries were Russia (458/1927, 23.8\%), Colombia (146/1927, 7.6\%), India (144/1927, 7.5\%), and Ethiopia (125/1927, 6\%). Since the most populated area of Russia is in Europe (and not in Asia), the data from Russia were entered in Europe.

Younger children came from Asia while the older were born in Americas (Table 1). Children aged 1 year or younger accounted for $2.6 \%$ of IAC, children between 1 and 4 years accounted for $39.2 \%$ of IAC, and children aged between 5 and 9 years accounted for $47.5 \%$ of IAC. Only $9.3 \%$ of the IAC were 10 to 14 years old, and older IAC belonging to the age group 15-18 years accounted for $1.3 \%$ of the population. IAC aged between 5 and 9 years represented the largest age group (Table 2).

Table 2. Continent of origin of the internationally adopted children (IAC) referred to Meyer Children's University Hospital, Florence, in the period (2009-2018), by age group (\%).

\begin{tabular}{cccccc}
\hline Age Group Year & $\begin{array}{c}\text { Africa \% } \\
(\boldsymbol{n}=\mathbf{3 4 7 )}\end{array}$ & $\begin{array}{c}\text { Americas \% } \\
(\boldsymbol{n}=\mathbf{4 1 9 )}\end{array}$ & $\begin{array}{c}\text { Asia \% } \\
(\boldsymbol{n}=\mathbf{3 8 4})\end{array}$ & $\begin{array}{c}\text { Europe \% } \\
(\boldsymbol{n}=\mathbf{7 7 7 )})\end{array}$ & $\begin{array}{c}\text { Total \% } \\
(\boldsymbol{n}=\mathbf{1 9 2 7})\end{array}$ \\
\hline$<1$ & 6.3 & 0.2 & 6.3 & 0.5 & 2.6 \\
$1-4$ & 47.6 & 21 & 48.2 & 40.8 & 39.2 \\
$5-9$ & 38.6 & 62.8 & 41.1 & 46.3 & 47.5 \\
$10-14$ & 5.5 & 14.6 & 3.6 & 11.1 & 9.3 \\
$15-18$ & 2 & 1.4 & 0.8 & 1.3 & 1.3 \\
\hline total & $18 \%$ & $21.7 \%$ & $19.9 \%$ & $40.3 \%$ & $100 \%$ \\
\hline
\end{tabular}

\subsection{Evaluation of the Immunological Coverage by Means of Serological Tests}

Most of the children enrolled by Meyer Children's University Hospital during the study period (2009-2018) were tested to evaluate the protective antibodies titers against measles, rubella, varicella, and mumps. Protective antibody titers were recorded in $64.9 \%$ of IAC for measles, in $60 \%$ for mumps, in $67.9 \%$ for rubella, and in $54 \%$ for varicella. Moreover, Africa was the continent with the highest percentage of unprotected children for measles $(p<0.0001)$, rubella $(p<0.0001)$, while IAC from Asia showed the highest percentage with unprotective antibodies for varicella $(p<0.0001)$ (Table 3).

Table 3. Percentage of children in the study with unprotective antibody titers (seronegative) against measles, rubella, varicella, and mumps, by continent of origin.

\begin{tabular}{lccccc}
\hline & $\begin{array}{c}\text { UNPROTECTED/Total } \\
\text { Number of Children for } \\
\text { Each Disease }\end{array}$ & $\begin{array}{c}\text { Africa } \\
(\boldsymbol{n}=347)\end{array}$ & $\begin{array}{c}\text { Americas } \\
(\boldsymbol{n}=\mathbf{4 1 9 )}\end{array}$ & Asia $(\boldsymbol{n}=384)$ & $\begin{array}{c}\text { Europe } \\
(\boldsymbol{n}=777)\end{array}$ \\
\hline $\begin{array}{l}\text { Measles } \\
\text { n/N (\%) }\end{array}$ & $657 / 1870(35.1 \%)$ & $156 / 337(46.3 \%)$ & $147 / 409(35.9 \%)$ & $159 / 377(42.2 \%)$ & $195 / 747(26.1 \%)$ \\
$\begin{array}{l}\text { Rubella } \\
\text { n/N (\%) }\end{array}$ & $600 / 1868(32.1 \%)$ & $139 / 337(41.3 \%)$ & $89 / 408(21.8 \%)$ & $136 / 373(36.5 \%)$ & $236 / 750(31.5 \%)$ \\
$\begin{array}{l}\text { Varicella } \\
\text { n/N (\%) }\end{array}$ & $290 / 631(46.0 \%)$ & $63 / 120(52.5 \%)$ & $42 / 134(31.3 \%)$ & $102 / 170(60.0 \%)$ & $83 / 207(40.1 \%)$ \\
$\begin{array}{l}\text { Mumps } \\
\text { n/N (\%) }\end{array}$ & $10 / 25(40.0 \%)$ & $2 / 15(13.3 \%)$ & $0 / 193(0.0 \%)$ & $5 / 122(4.1 \%)$ & $3 / 514(0.6 \%)$ \\
\hline
\end{tabular}


The large majority of children $<1$ year of age were unprotected against the four VPDs investigated. Moreover, $57.7 \%$ of older children were unprotected for measles ${ }^{*} p<0.001$ for measles and varicella in 1-4 y vs. 15-18 y). In the age group 1-4 years, 36\% of IAC were unprotected for measles, 35\% for rubella, and $69 \%$ for varicella (Figure 1 ).

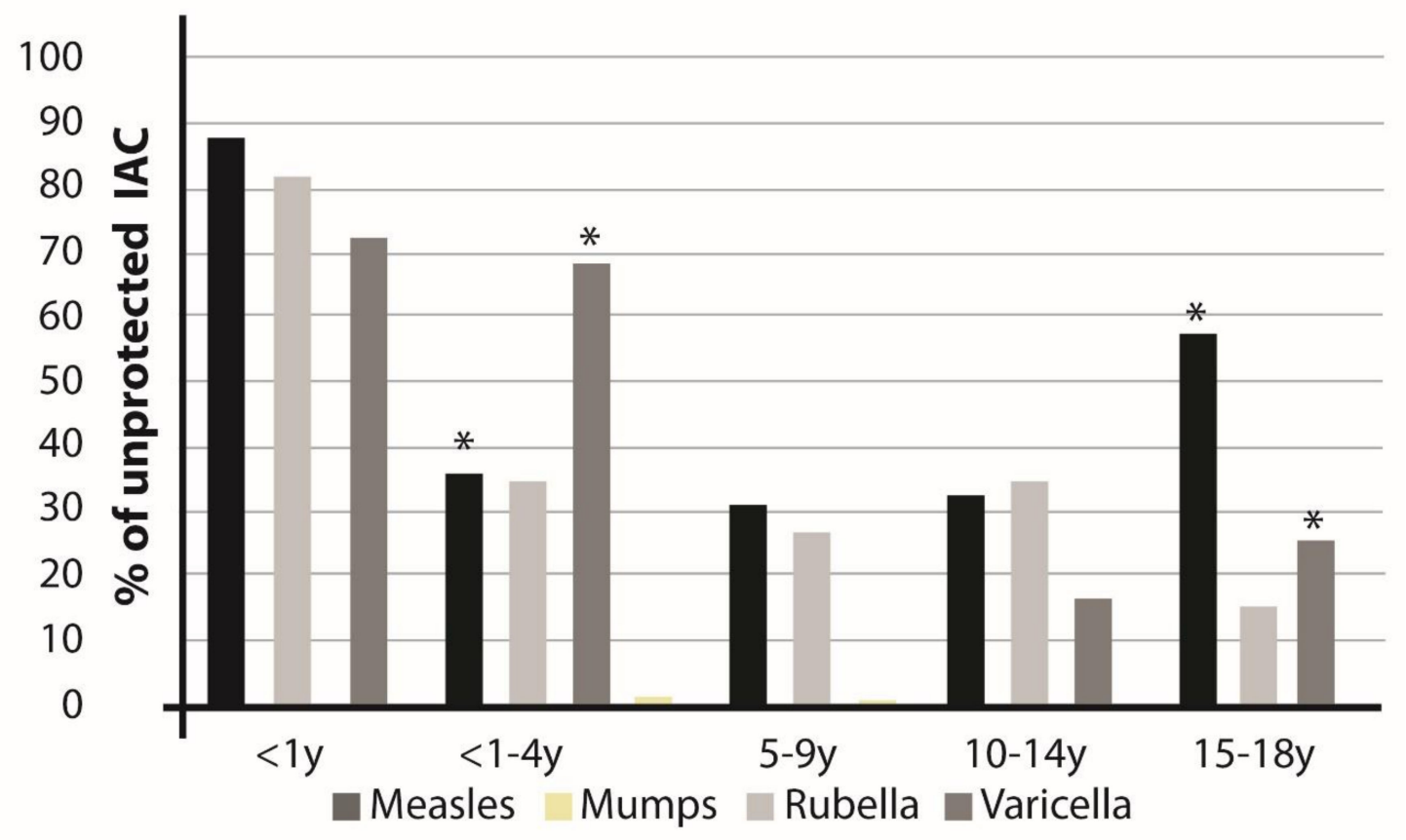

Figure 1. Percentage of internationally adopted children (IAC) with unprotective antibody titers (seronegative) by age groups.

From ages 5 and up to 14 years, we observed the highest percentage of protected IAC.Notably, almost $60 \%$ of children aged $15-18$ years were unprotected for measles.

Documentation of the vaccine received in the country of origin was not always available (Table 4). In particular, a discrepancy between documentation indicating previous vaccinations and unprotective (seronegative) antibody titers was evidenced in $25.6 \%$ of the children for measles, $24.9 \%$ for rubella, $53.3 \%$ for varicella, and $25 \%$ for mumps (Table 4 ).

Table 4. Comparison between documentation recorded and serological tests performed in Italy.

\begin{tabular}{cccccc}
\hline VPD & $\begin{array}{c}\text { Immunization Status According } \\
\text { to Documentation } \boldsymbol{n}(\mathbf{\%})\end{array}$ & $\begin{array}{c}\text { Immunization Status According } \\
\text { to Serological Test } \boldsymbol{n} \mathbf{( \% )}\end{array}$ & Total & \\
\hline \multirow{2}{*}{ Measles } & & Protected & Unprotected & & \\
& Recorded & $717(74.4)$ & $247(25.6)$ & 964 & $p<0.001$ \\
Rubella & Not recorded & $496(54.7)$ & $410(45.3)$ & 906 & \\
& Recorded & $674(75.1)$ & $223(24.9)$ & 897 & $p<0.001$ \\
Varicella & Not recorded & $594(61.2)$ & $377(38.8)$ & 971 & $p=0.172$ \\
& Recorded & $35(46.7)$ & $40(53.3)$ & 75 & \\
Mumps & Not Recorded & $306(55.0)$ & $250(45.0)$ & 556 & \\
& Recorded & $6(75.0)$ & $2(25.0)$ & 8 & $p=0.294$ \\
\hline
\end{tabular}

By evaluating the serological results according to documentation records and age groups, it is evident that under 1 year of age there was a high percentage of IAC without serological protection: $87.75 \%$ for measles, $82.35 \%$ for rubella, and $72.73 \%$ for varicella (Figure 1 ). 
The discrepancy between serological results and vaccine documentation was reported in Africa from $49 \%$ to $54 \%$ depending on the disease considered. For Americas, the discrepancy varied from $47 \%$ to $70 \%$. The discrepancy varied for Asia from 35\% to $42 \%$ and for Europe from 33\% to 58\% (Table 5).

Table 5. Number and percentage of IAC with concordance and discordance between documentation records and serological results by continent of origin and age group.

\begin{tabular}{|c|c|c|c|c|c|c|c|}
\hline \multirow{2}{*}{$\begin{array}{c}\text { Continent } \\
\text { Africa }\end{array}$} & \multirow{3}{*}{$\begin{array}{c}\text { Concordance/Discordance } \\
\text { Concordance } \\
\text { Discordance }\end{array}$} & \multicolumn{2}{|c|}{ Measles } & \multicolumn{2}{|c|}{ Rubella } & \multicolumn{2}{|c|}{ Varicella } \\
\hline & & 168 & $49.85 \%$ & 154 & $45.70 \%$ & 61 & $50.83 \%$ \\
\hline & & 169 & $50.15 \%$ & 183 & $54.30 \%$ & 59 & $49.17 \%$ \\
\hline Total & & 337 & & 337 & & 120 & \\
\hline \multirow[t]{2}{*}{ Americas } & Concordance & 214 & $52.32 \%$ & 212 & $51.96 \%$ & 40 & $29.85 \%$ \\
\hline & Discordance & 195 & $47.68 \%$ & 196 & $48.04 \%$ & 94 & $70.15 \%$ \\
\hline Total & & 409 & & 408 & & 134 & \\
\hline \multirow[t]{2}{*}{ Asia } & Concordance & 245 & $64.99 \%$ & 234 & $62.73 \%$ & 97 & $57.06 \%$ \\
\hline & Discordance & 132 & $35.01 \%$ & 139 & $37.27 \%$ & 73 & $42.94 \%$ \\
\hline Total & & 377 & & 373 & & 170 & \\
\hline \multirow[t]{2}{*}{ Europe } & Concordance & 500 & $66.93 \%$ & 451 & $60.13 \%$ & 87 & $42.03 \%$ \\
\hline & Discordance & 247 & $33.07 \%$ & 299 & $39.87 \%$ & 120 & $57.97 \%$ \\
\hline Total & & 747 & & 750 & & 207 & \\
\hline \multicolumn{8}{|l|}{ Age group } \\
\hline \multirow[t]{2}{*}{$<1 \mathrm{yrs}$} & Concordance & 43 & $87.76 \%$ & 41 & $80.39 \%$ & 8 & $72.73 \%$ \\
\hline & Discordance & 6 & $12.24 \%$ & 10 & $19.61 \%$ & 3 & $27.27 \%$ \\
\hline Total & & 49 & & 51 & & 11 & \\
\hline \multirow[t]{2}{*}{$1-4$ yrs } & Concordance & 455 & $62.24 \%$ & 473 & $64.97 \%$ & 143 & $67.14 \%$ \\
\hline & Discordance & 276 & $37.76 \%$ & 255 & $35.03 \%$ & 70 & $32.86 \%$ \\
\hline Total & & 731 & & 728 & & 213 & \\
\hline \multirow[t]{2}{*}{$5-9$ yrs } & Concordance & 514 & $58.08 \%$ & 444 & $50.17 \%$ & 111 & $36.27 \%$ \\
\hline & Discordance & 371 & $41.92 \%$ & 441 & $49.83 \%$ & 195 & $63.73 \%$ \\
\hline Total & & 885 & & 885 & & 306 & \\
\hline \multirow[t]{2}{*}{$10-14$ yrs } & Concordance & 102 & $56.98 \%$ & 88 & $49.44 \%$ & 17 & $21.79 \%$ \\
\hline & Discordance & 57 & $31.84 \%$ & 90 & $50.56 \%$ & 61 & $78.21 \%$ \\
\hline Total & & 179 & & 178 & & 78 & \\
\hline \multirow[t]{2}{*}{$15-18$ yrs } & Concordance & 13 & $50.00 \%$ & 5 & $19.23 \%$ & 6 & $26.09 \%$ \\
\hline & Discordance & 13 & $50.00 \%$ & 21 & $80.77 \%$ & 17 & $73.91 \%$ \\
\hline Total & & 26 & & 26 & & 23 & \\
\hline
\end{tabular}

Note: Concordance $=$ seropositive IAC with documentation of previous vaccination and seronegative with unrecorded vaccination. Discordance $=$ seropositive IAC despite the absence of vaccination records and seronegative while the documentation attests the vaccination as received.

Considering age groups, discrepancies were observed from $12 \%$ to $27 \%$ for IAC $<1$ year of age, from $33 \%$ to $38 \%$ for IAC from 1 to 4 years of age, from $42 \%$ to $64 \%$ for IAC from 5 to 9 years of age, from $32 \%$ to $78 \%$ for IAC from 10 to 14 years of age, and for adolescences $15-18$ years of age from $50 \%$ to $73 \%$.

According to documentation of vaccinations, except for mumps vaccination records, most children did not receive any dose of vaccine (Table 6). Most IAC $<1$ year of age had no documentation of vaccination. More often IAC from 1-4 and from 5-9 age groups had some documentation of previous vaccination. Particularly, children in the 5-9 age group were those who had more frequently recorded the second dose. 
Table 6. Number of doses documented for IAC by age groups.

\begin{tabular}{|c|c|c|c|c|}
\hline & Age Group & 0 Dose & 1 Dose & 2 Doses \\
\hline \multirow{5}{*}{ Measles $(n=1870)$} & $<1 \mathrm{y}$ & 45 & 4 & 0 \\
\hline & $1-4 y$ & 368 & 318 & 45 \\
\hline & $5-9 y$ & 446 & 246 & 193 \\
\hline & $10-14 y$ & 93 & 33 & 53 \\
\hline & $15-18 y$ & 20 & 3 & 3 \\
\hline \multirow{5}{*}{ Rubella $(n=1868)$} & $<1 \mathrm{y}$ & 50 & 1 & 0 \\
\hline & $1-4 y$ & 407 & 296 & 25 \\
\hline & $5-9 y$ & 455 & 258 & 172 \\
\hline & $10-14 y$ & 102 & 32 & 44 \\
\hline & $15-18$ y & 23 & 2 & 1 \\
\hline \multirow{5}{*}{ Varicella $(n=631)$} & $<1 \mathrm{y}$ & 11 & 0 & 0 \\
\hline & $1-4 y$ & 186 & 23 & 4 \\
\hline & $5-9 y$ & 273 & 25 & 8 \\
\hline & $10-14 y$ & 75 & 2 & 1 \\
\hline & $15-18 y$ & 23 & 0 & 0 \\
\hline \multirow{5}{*}{ Mumps $(n=844)$} & $<1 \mathrm{y}$ & 3 & 0 & 0 \\
\hline & $1-4 y$ & 6 & 286 & 23 \\
\hline & $5-9 y$ & 7 & 258 & 178 \\
\hline & $10-14$ y & 1 & 33 & 45 \\
\hline & $15-18 y$ & 0 & 3 & 1 \\
\hline
\end{tabular}

\section{Discussion}

In the current study we analyzed the measles-mumps-rubella-varicella (MMRV) vaccination status and serological data available in a large population of IAC referred to a single center in Tuscany (Italy) over a 10-year period. To our knowledge, this is one of the most numerous studies including data from more than 1900 IAC collected over a 10-year period. A large proportion of children resulted seronegative toward measles $(35.1 \%)$, rubella $(32.1 \%)$, varicella $(45.9 \%)$, and mumps $(40 \%)$. These figures are more pronounced considering African children for measles and rubella $(46.3 \%$ and $41.2 \%$, respectively) and Asian children for varicella (60\%). As expected, children $<1$ year of age were more commonly unprotected (72-88\%), as the first dose of MMR-V vaccine is recommended between 12 and 15 months of age. The second dose is recommended during childhood. The minimum interval between first dose and second dose is 4 weeks. In Italy the second dose is recommended at 5-6 years of age. Age group 1-4 years may have only received 1 dose and would not be fully protected. Our results show that in the age group 1-4 years, a percentage between $35-69 \%$ of children were unprotected (Figure 1) particularly for measles, rubella, and varicella. From ages 5 and up to 14 years, we observed the highest percentage of protected IAC. Notably, almost $60 \%$ of children aged $15-18$ years were unprotected for measles, representing an age group which should be considered particularly at high risk. It shouldn't be taken for granted that adolescents have already received vaccination against MMRV or have already acquired the infection.

Several studies assessing the proportion of children (IAC and migrants) with protective antibody titers against different VPDs are available. These studies reported a high variability of antibody protection rates. In particular, protective antibody titers were reported in a range of $12-95 \%$ for measles, $61-94 \%$ for rubella, $48-79 \%$ for mumps, and $30-100 \%$ for varicella. Our data/results were in accordance with the results of previous studies [6,11,14-16,19-30].

The written documentation of the IAC may not accurately reflect the immunization status [24,29].

The lack of vaccine documentation reliability has been reported in literature and numerous studies have correlated this unreliability with no protection or under-immunization [14,20,22,30-32]. Our data underline the poor reliability of vaccine documentation, when available: Discrepancies between serological test results and vaccine documentation were observed in about one-quarter of IAC for MMR and more than half the children for varicella. 
These studies report a variable documentation reliability in the range of $62-83 \%$ for measles, $38-86 \%$ for rubella, $55-75 \%$ for mumps, and $47-91 \%$ for varicella. In particular, in the most recent study conducted by Giordano et al., the reliability of the documentation for measles, mumps, rubella, and hepatitis B were assessed [14]. This study showed a concordance between protective antibody titers and written documentation stating the vaccinations which had been carried out in the country of origin. The concordance was $78 \%$ for measles, $65.2 \%$ for mumps, $83.6 \%$ for rubella, and $71.2 \%$ for hepatitis B [14].

According to the literature, IAC's place of birth has been described to be related with the reliability of immunization records. For example, African and Central American IAC had a lack of vaccine documentation compared with Eastern European and Asian IAC [32]. Some authors have reported that certificates were written with the same pencil, reported in the same date of consecutive months, or even dated before the child's birth [22]. Some other obstacles identified when reviewing the immunization records were translation issues and misinterpretation of written reported brand name of the vaccine.

Any vaccines the children may have received could be ineffective due to suboptimal storage and transport or because they were administered after the expiration date [16,17]. IAC are often malnourished and have severe co-infections or immunodeficiencies and these increase their risk of immunization failure $[19,20]$.

Despite the existence of vaccination records, these can be unreliable and justify the importance of serology test promptly after the arrival of IAC.

Our study has several limitations. During the 10-year study period some investigations included in the screening protocol changed, and some tests were not performed in the whole population: In fact, the large majority of the children referred to Meyer Children's University Hospital and included in the study were evaluated as per protocol, but for some variables some data were missing, possibly due to the physicians' incomplete adherence to the screening protocol or to an incomplete collection of data in medical records. Indeed, it must be considered that our center was able to recruit only a part of all the adopted children arriving in Tuscany, as some parents may have consulted their primary care pediatrician or no one at all. Lastly, there is no absolute association between being unprotected and not having protective antibody titers, since immune response to vaccines is complex and relies on different immunologic mechanisms, which are not all explored by serology testing [33].

\section{Conclusions}

Our data underline the importance of a rapid, careful, and complete assessment of immunization status in IAC. Many factors, such as lack of public health infrastructure or maintenance of the cold chain for the storage of the vaccines or malnutrition especially in low- and middle-income countries, influence the serological pattern of these children. This study highlighted that more than half of the newly arrived IAC were unprotected against MMRV. Notably, even if vaccination documentation of the country of origin was available, this was not always reliable: a quarter of the IAC were not protected in the current study. Our data suggest that vaccination status and serological assessment should be promptly performed on all IAC after their arrival in order to prevent outbreaks of VPDs.

Author Contributions: Conceptualization, E.C., A.B., and S.B.; data curation, C.M.A., A.B., and S.B.; formal analysis, C.M.A., A.B., and S.B., funding acquisition, L.G.; E.C., S.B., and A.B.; validation, P.B., L.G., and E.C.; investigation, C.M.A.; resources, E.C. and L.G.; writing-original draft preparation, A.B. and C.M.A; writing-review and editing, all authors; visualization: P.B., A.B., C.M.A., and L.G.; supervision, L.G..; project administration, E.C. All authors have read and agreed to the published version of the manuscript.

Funding: This research was partially supported by the Cassa di Risparmio di Firenze funded by Cassa di Risparmio, grant number 24151.

Conflicts of Interest: The authors declare no conflict of interest. The funders had no role in the design of the study; in the collection, analyses, or interpretation of data; in the writing of the manuscript, or in the decision to publish the results. 


\section{References}

1. European Centre for Disease Prevention and Control. Public health guidance on screening and vaccination for infectious diseases in newly arrived migrants within the EU/EEA. Available online: https://www.ecdc.europa.eu/sites/portal/files/documents/Public\%20health\%20guidance\%20on\%20screening\% 20and\%20vaccination\%20of\%20migrants\%20in\%20the\%20EU\%20EEA.pdf (accessed on 1 August 2019).

2. World Health Organization. Measles no longer endemic in 79\% of the WHO European Region. Available online: http://www.euro.who.int/en/media-centre/sections/press-releases/2017/measles-no-longer-endemicin-79-of-the-who-european-region (accessed on 2 September 2019).

3. World Health Organization. European Region loses ground in effort to eliminate measles. Available online: http://www.euro.who.int/en/media-centre/sections/press-releases/2019/european-regionloses-ground-in-effort-to-eliminate-measles (accessed on 2 September 2019).

4. European Centres for Disease Prevention and Control. Measles. Available online: https://www.ecdc.europa. eu/en/measles (accessed on 15 August 2019).

5. The Portal of Epidemiology for Public Health by the Italian National Institute of Health. Latest updates. Available online: https://www.epicentro.iss.it/morbillo/aggiornamenti (accessed on 14 January 2020).

6. Dixit, D.; Rajapakse, N.; Kuhn, S. Caring for kids new to Canada Immunizations: Bringing Newcomer Children Up-to-date. 2018. Available online: https://www.kidsnewtocanada.ca/screening/immunizations (accessed on 15 August 2019).

7. Ministry of Health. National Vaccine Prevention Plan (PNPV) 2017-2019. Available online: https://www. gazzettaufficiale.it/eli/id/2017/02/18/17A01195/sg (accessed on 3 January 2020).

8. Ministry of Health. Vaccinations of the Pediatric and Adolescent age-Vaccination Coverage. Available online: http: //www.salute.gov.it/portale/documentazione/p6_2_8_3_1.jsp?lingua=italiano\&id=20) (accessed on 3 January 2020).

9. Nardone, A.; de Ory, F.; Carton, M.; Cohen, D.; van Damme, P.; Davidkin, I.; Rota, M.C.; de Melker, H.; Mossong, J.; Slacikova, M. The comparative sero-epidemiology of varicella zoster virus in 11 countries in the European region. Vaccine 2007, 25, 7866-7872. [CrossRef] [PubMed]

10. Bechini, A.; Boccalini, S.; Baldo, V.; Cocchio, S.; Castiglia, P.; Gallo, T.; Giuffrida, S.; Locuratolo, F.; Tafuri, S.; Martinelli, D. Impact of universal vaccination against varicella in Italy. Hum. Vaccin. Immunother. 2015, 11, 63-71. [CrossRef] [PubMed]

11. Boccalini, S.; Bonanni, P.; Bechini, A. Preparing to introduce the varicella vaccine into the Italian immunisation programme: Varicella-related hospitalisations in Tuscany, 2004-2012. Euro Surveill. 2016, 21. [CrossRef] [PubMed]

12. Pieri, L.; Porchia, B.R.; Pieralli, F.; Varone, O.; Niccolai, G.; Roselli, A.; Boccalini, S.; Bonanni, P.; Bechini, A. Working Group of Tuscan LHU's; Working Group of Tuscan LHU's. Assessment of the effectiveness of the universal varicella vaccination program in Toscana (Italy), in the period 2010-2013. Epidemiol. Prev. 2015, 39, 119-123.

13. Commission for Intercountry Adoptions. Data and Perspectives in Intercountry Adoptions. Summary Report Dossiers from 2016 to 2017. Available online: http://www.commissioneadozioni.it/media/1564/57b8c summary_report_cai_en.pdf (accessed on 3 September 2019).

14. Giordano, D.; Provenzano, S.; Santangelo, O.; Piazza, D.; Ferraro, D. Active immunization status against measles, mumps, rubella, hepatitis B in internationally adopted children, surveyed at the university hospital of Palermo, Sicily. Ann. Ig. 2018, 30, 431-435.

15. De Monléon, J.; Regnier, F.; Ajana, F.; Baptiste, C.; Callamand, P. Mise à jour des vaccinations de 1 ' enfant arrivant de 1 ' étranger ( adopté, réfugié ou migrant ) en France Catch-up vaccination of worldwide newcoming (adopted, refugee or migrant) children in France. Arch. Pediatr. 2014, 21, 329-334. [CrossRef]

16. Schulte, J.; Maloney, S.; Aronson, J.; Gabriel, P.; Zhou, J.; Saiman, L. Evaluating Acceptability and Completeness of Overseas Immunization Records of Internationally Adopted Children. Pediatrics 2002, 109, 2-5. [CrossRef]

17. Centers for Disease Control and Prevention. CDC Yellow Book 2020: Health information for international Travel. International Adoption. Available online: https://wwwnc.cdc.gov/travel/yellowbook/2020/familytravel/international-adoption (accessed on 8 September 2019).

18. World Health Organization. Vaccine-Preventable Diseases: Morning System 2019 Global Summary. 2019. Available online: http://apps.who.int/immunization_monitoring/globalsummary/diseases (accessed on 15 August 2019). 
19. Sollai, S.; Ghetti, F.; Bianchi, L.; De Martino, M.; Galli, L.; Chiappini, E. Infectious diseases prevalence, vaccination coverage, and diagnostic challenges in a population of internationally adopted children referred to a Tertiary Care Children's Hospital from 2009 to 2015. Medicine 2017, 96, 1-10. [CrossRef]

20. Viviano, E.; Cataldo, F.; Accomando, S.; Firenze, A.; Maria, R.; Romano, N. Immunization status of internationally adopted children in Italy. Vaccine 2006, 24, 4138-4143. [CrossRef]

21. Giambi, C.; Del Manso, M.; Marchetti, G.; Olsson, K.; Adel Ali, K.; Declich, S.; Venice Survey Working Group. Immunisation of migrants in EU/EEA countries: Policies and practices. Vaccine 2019, 37, 5439-5451. [CrossRef]

22. Schulpen, T.; van Seventer, A.; Rümke, H.; van Loon, A. Immunisation status of children adopted from China. Lancet 2001, 358, 2131-2132. [CrossRef]

23. Miller, L.C.; Tseng, B.; Tirella, L.G.; Chan, W.; Feig, E. Health of Children Adopted from Ethiopia. Matern. Child Health J. 2008, 100, 599-605. [CrossRef] [PubMed]

24. Cilleruelo, M.; de Ory, F.; Ruiz-Contrerasc, J.; González-González, R.; Mellado, M.; Garcia-Hortelanoa, M.; Herruzoe, R. Internationally adopted children: What vaccines should they receive. Vaccine 2008, 26, 5784-5790. [CrossRef] [PubMed]

25. Staat, M.A.; Stadler, L.P.; Donauer, S.; Trehan, I.; Rice, M.; Salisbury, S. Serologic testing to verify the immune status of internationally adopted children against vaccine preventable diseases. Bone 2010, 23, 1-7. [CrossRef] [PubMed]

26. Chiappini, E.; Zaffaroni, M.; Bianconi, M.; Veneruso, G.; Grasso, N.; Garazzino, S.; Bona, G. Italian multicentre study found infectious and vaccine-preventable diseases in children adopted from Africa and recommends prompt medical screening. Acta Paediatr. 2018, 107, 1581-1586. [CrossRef] [PubMed]

27. Stadler, L.; Mezoff, A.; Staat, M. Hepatitis B Virus Screening for Internationally Adopted Children. Pediatrics 2008, 122, 1223-1228. [CrossRef]

28. Jones, V.F.; Committee On Early Childhood, Adoption, and Dependent Care. Comprehensive health evaluation of the newly adopted child. Pediatrics 2012, 129, e214-e223. [CrossRef]

29. Verla-tebit, E.; Zhu, X.; Holsinger, E.; Mandalakas, A.M. Predictive Value of Immunization Records and Risk Factors for Immunization Failure in Internationally Adopted Children. Arch. Pediatr. Adolesc. Med. 2009, 163, 473-479. [CrossRef]

30. Miller, L.; Chan, W.; Comfort, K.; Tirella, L. Health of Children Adopted From Guatemala: Comparison of Orphanage and Foster Care. Pediatrics 2005, 115, 710-717. [CrossRef]

31. Italian Pediatric Society. New indications of the GLNBI-SIP (Working group for the migrant child of the Italian Pediatric Society) for the health care of the migrant minor. In Proceedings of the Consensus Conference GLNBI-SIP, Rome, Italy, 30 November 2013.

32. Venturini, E.; Piccini, P.; Tersigni, C.; Chiappini, E.; Galli, L. Systematic review shows that immunising internationally adopted children is a major challenge for primary health care. Acta Paediatr. 2019, 108, 411-418. [CrossRef]

33. Woudenberg, T.; van Binnendijk, R.; Veldhuijzen, I.; Woonink, F.; Ruijs, H.; van der Klis, F.; Kerkhof, J.; de Melker, H.; de Swart, R.; Hahné, S. Additional Evidence on Serological Correlates of Protection against Measles: An Observational Cohort Study among Once Vaccinated Children Exposed to Measles. Vaccines 2019, 7, 158. [CrossRef] [PubMed]

(C) 2020 by the authors. Licensee MDPI, Basel, Switzerland. This article is an open access article distributed under the terms and conditions of the Creative Commons Attribution (CC BY) license (http://creativecommons.org/licenses/by/4.0/). 